\title{
De universitaire opleiding tot accountant; (Primus) inter Pares?
}

\author{
Prof. Drs. G.G.M. Bak
}

\section{Wat vooraf ging....}

- Nog altijd geldt, en wel in het bijzonder in dit beroep, dat 'the proof of the pudding is in the eating'. Dit citaat uit een MAB-artikel anno 1955 van de hand van J. Kralayenhof is een passend begin voor mijn beschouwing in dit jubileumnummer van het $\mathrm{MAB}$ over de universitaire opleiding tot accountant. Kraayenhof mengde zich met dit artikel in het met name door de Groningse hoogleraar J.L. Mey aangespannen debat rond de opleiding tot accountant: Universiteit of Instituut: moet uiteindelijk voorkeur worden gegeven aan een academische of aan een door het beroep georganiseerde opleiding? J.L. Mey (1953) had met klem van argumenten gepleit voor het primaat van de academische weg, met zoveel klem zelfs dat het geen vraag meer leek naar de 'Primus inter Pares', maar veeleer of nog wel van 'inter Pares' gesproken kon worden. Het door Kraayenhof weergegeven resultaat van de 'twee-happenproef' wil ik de MAB-lezer anno 1995 niet onthouden: 'Welnu', aldus Kraayenhof - 'ik meen dat men niet kan zeggen dat de door de beide opleidingen afgeleverde accountants in het algemeen gesproken "dooreenleverbaar" zijn of worden. Uiteraard is dit voor een deel hunner wel het geval: men denke aan de niet-academisch gevormde die, door annleg en/of aanvullende studie, in economische kennis en bekwaamheid tot het hanteren daarvan, niet

Prof. Drs. G.G.M. Bak RA is Hoogleraar Accountancy aan de Katholieke Universiteit Brabant en Buitengewoon Raadadviseur van het ministerie van Justitie in Jaarrekeningzaken. Als openbaar accountant was hij tot 1993 verbonden aan Coopers \& Lybrand accountants. voor de academisch opgeleide onderdoet, en aan de academisch gevormde die door aunleg en volharding zijn achterstand in praktische ervaring weet in te halen'. Beide groepen vinden elkilar in de accountantskantoren en vullen elkaar zeer goed aan, aldus Kraayenhof; geen behoefte dus om een primus inter pares aan te wijzen.

Behalve de relatie tussen verschillend opgeleide beroepsgenoten onderling was in het MABdebat uit de vijftiger jaren ook het 'maatschappelijk alanzien' van de beroepsbeoefenaren alan de orde. J.L. Mey (t.a.p.) hanteerde daartoe het criterium, dat 'de accountant in staat moet zijn zich op het hoogste niveau in het bedrijfsleven te bewegen en zich daar ook te kunnen laten gelden als onathankelijk en onbevooroordeeld deskundige'. Uiteraard werd dit door Kraayenhof niet bestreden: de debaters verschilden slechts van mening over de vraag in hoeverre de niet-academische beroepsopleiding van die tijd daartoe de vereiste bekwaamheid kon opleveren. Het 'inter Pares' krijgt in deze benadering een andere dimensie: ook ten opzichte van hun tegenspelers in de cliëntorganisatie dienen accountants zich als 'Peers' te kunnen bewegen. Het is tenslotte niet toevallig dat het engelse 'Peers' afkomstig is van het latijnse 'Pares'. Het is met name deze gelijkwaardigheid in academisch opleidingsniveau tussen accountants en hun cliënten die ik in deze beschouwing aan de orde wil stellen.

Alvorens tot het heden terug te keren is het van belang de verdere gang van zaken rond het MABdebat uit de vijftiger jaren kort weer te geven. Tijdens de parlementaire behandeling van het ontwerp voor de eerste Wet op de Registeraccountants anno 1959 is van de zijde van de Groningse Universiteit nog bepleit academische en nietacademische accountants in afzonderlijke beroeps- 
organisaties onder te brengen. Het valt niet moeilijk achter deze démarche de hand van J.L. Mey te zien, de Groningse hoogleraar, die zich blijkbaar niet door het evenwichtige standpunt van zijn debater uit 1955 had laten overtuigen. De regering liet zich daardoor niet van zijn stuk brengen en hield vast aan het uitgangspunt dat het bij de wet ingestelde examen van gelijkwaardig niveau zou kunnen en moeten zijn als de universitaire examens. Een en ander werd mede gebaseerd op de pragmatische overweging dat de universiteiten de onderwijslast van zo'n vergrote instroom niet aan zouden kunnen (Regelingen 1984).

Onder het regime van de Wet op de Registeraccountants 1962 is deze tegenstelling snel buiten beeld geraakt, mede door de heilzame samensmelting van NIVA en VAGA binnen het NIVRA en de groei van de accountantskantoren. In de beroepspraktijk blijken accountants uit beide opleidingssystemen in feite 'dooreenleverbaar' te zijn. Daardoor kon ook in de tachtiger jaren een niet onbelangrijke rolwisseling betrekkelijk geruisloos plaatsvinden: sprak de minister anno 1960 nog over gelijkwaardigheid van de NIVRA-opleiding aan de universitaire, in die jaren werd de accrediteringsfunctie toegekend aan het NIVRA-Examenbureau. Ook de nieuwe Wet op de Registeraccountants anno 1993 regelt het afgeven (en intrekken) van verklaringen van gelijkwaardigheid door het Examenbureau aan de universiteiten. Door het onlangs tot stand gekomen verbond tussen de NIVRA-opleiding en de Universiteit van Nijenrode lijkt de definitieve stap naar gelijkschakeling op academisch niveau gezet.

\section{Het postdoctorale beroepsonderwijs}

De hiervoor beschreven rolwisseling werd vooral veroorzaakt door een andere visie op de rol van de universiteiten in het beroepsgericht onderwijs. In het kader van de twee-fasenstructuur werd van de universiteiten verwacht dat zij in samenwerking met de afnemers opleidingen zouden ontwikkelen die qua bekostiging en qua inhoudsbepaling niet meer onder verantwoordelijkheid van de minister van $O \& W$ zouden vallen. Met het vervallen van het Academisch Statuut moest daarom ook de wettelijke basis onder het universitaire accountantsexamen veranderen. Aan deze ontwikkeling heb ik destijds uitvoerig aandacht besteed in De Accountant (Bak 1986). Ik heb er toen voor gepleit open oog te houden voor het feit dat hier meer aan het veranderen was dan alleen de wettelijke basis onder het accountantsexamen. Het liet zich toen reeds aanzien wat zich aan de universiteiten zou gaan afspelen: nauwere samenwerking met het bedrijfsleven en overige 'afnemers', teneinde te komen tot beroepsgericht naervaringsonderwijs. De tijd van academisch isolement - kenmerk van de jaren zeventig - was voorbij, een periode van constructieve samenwerking leek aangebroken. De minister van O\&W heeft de afgelopen jaren ruim $f 100$ miljoen besteed aan startsubsidies om deze ontwikkeling te stimuleren. Inmiddels blijkt dit beleid goed te zijn aangeslagen. Aan de technische universiteiten, in de bestuurs- en bedrijfskunde, maar vooral ook aan de economische faculteiten zijn - in financieel opzicht 'self-supporting' - beroepsopleidingen tot stand gekomen waar afgestudeerden van universiteiten en HBO zich verder kunnen bekwamen. De doelgroep bestaat typisch uit veelbelovende jonge mensen die in hun werkomgeving in staat worden geacht 'carrière' te maken; doorgaans is dit immers de voorwaarde waarop een organisatie bereid zal zijn zich de noodzakelijke investering te getroosten in cursusgelden en belangrijker - afwezigheid uit functie! Voor veel lezers van het MAB zijn deze opleidingen ongetwijfeld bekend terrein: naast de MBA-opleidingen die veelal in samenwerking met een buitenlandse universiteit worden georganiseerd heeft de controllersopleiding aan de VU zich in de loop der jaren een gerenommeerde positie verworven in financieel-economisch Nederland; dit voorbeeld vindt dan ook op ruime schaal navolging. Ook kan worden gewezen op de succesvolle EDP-audit opleidingen aan verschillende universiteiten. De KUB - de universiteit waaraan schrijver dezes is verbonden - heeft deze activiteiten in een suprafacultaire, professionele organisatie ondergebracht. Dit Tilburgs Instituut voor Academische Studies (TIAS) genereert met ca. 10 opleidingen op het gebied van functioneel management een jaarlijkse geldstroom van ruim $f 5$ miljoen. De opleidingsbrochure vermeldt onder meer opleidingen in Bestuurlijke Informatiekunde (BIK), Financieel Economisch Management (FEM), Management \& Organisatie, Marketing College, Strategie en Management van de Gezondheidszorg, Overheidsaccountancy en EDP-Auditing. Onlangs werd met enig vertoon de duizendste cursist ingeschreven. De gemiddelde leeftijd van deze 'studenten' bedroeg 37 jaar, waaruit reeds 
duidelijk blijkt dat hier sprake is van een andere doelgroep dan met de postdoctorale accountantsopleiding word bereikt. De betekenis van deze 'wapenfeiten" dringt pas door tol wie zich realiseert dat iedere student "in de marki" moet worden aangetrokken. Zowel bij betrokkene als bij haar of zijn werkgever moet de overtuiging bestaan dat men waar voor zijn geld krijgt en dat is niet gering bij een cursusduur - in deeltijd - van 1.5 tot 2 jaar en een cursusgeld van $f 30.000$ tot $f 40.000$.

\section{Kwalificatie en titulatuur}

Zowel bij studenten als bij de "afnemers" blijkt behoefte te bestaan aan een herkenbare kwalificatie en bijbehorende titulatuur voor deze nieuwe academische beroepsopleidingen. Deze dienen tevens als aanduiding van het met de opleiding verbonden $k$ waliteitsniveau. Een aantal opleidingen zoekt aansluiting bij de ingeburgerde aanduiding 'register....' en legt daartoe dan ook een register aan van degenen die de opleiding met goed gevolg hebben gevolgd. Terzijle merk ik op dat niemand zich blijkbaar stoort aan de verwarring die bij het publiek zou kunnen ontstaan nu deze aanduiding dooreen gebruikt wordt voor bij wet ingestelde registers met een publiekrechtelijk karakter en voor op privaatrechtelijke leest geschoeide registers. Dit zou een aanwijzing kunnen zijn dal belanghebbenden meer belang hechten aan de intrinsieke betekenis van een kwalificatie dan aan de formeel juridische status daarvan.

Andere opleidingen maken gebruik van de Masterstitel. Aanvankelijk bestond er in universitaire kring grote aarzeling om deze aanduiding in dit verband te galan hanteren. De bescherming die deze titel geniet in internationaal verband is slechts bescheiden van aard, zodat in vele gevallen kan worden gesteld dat het niveau van de deshetreffende opleidingen beneden dat van het Doctoraalexamen aan een Nederlandse Universiteit ligt. Het leek dus niet voor de hand te liggen postdoctorale kwalificaties met een Masterstitel te honoreren. Anderzijds is met name in de internationale bruikbaarheid van de titel een groot voordeel gelegen. Uiteindelijk is de Vereniging van Samenwerkende Universiteiten (VSNU) voor dit laatste - pragmatische - argument gezwicht en heeft zij in 1991 een leidraad opgesteld voor de toekenning van Masterstitels door Nederlandse Universiteiten. In het onnavolgbaar jargon van de universitaire bureaucratie wordt deze titel met name gereserveerd voor 'peridoctorale' opleidingen, dat zijn opleidingen die meer verbredend dan verdiepend zijn en een instroom toelaten die divers is naar vakgebied. Tot de gestelde voorwaarden behoren onder meer een ingangsniveau op universitair of HBO-niveau en een cursusduur van ten minste een jaar (VSNU 1991).

\section{Primus inter pares}

De lezer zal zich wellicht afvragen wat dit alles met de universitaire accountantsopleiding te maken heeft: was dat al niet een academische beroepsopleiding 'avant la lettre', die inmiddels ook financieel op eigen benen staat? Is de samenwerking tussen opleiding en beroep al niet voldoende gewalarborgd door de figuur van deeltijds hoogleraar zoals die daar van de aanvang af heeft gefunctioneerd? De accountantsopleidingen hadden in vele opzichten een voorsprong op de nicuwe tweede-fase-opleidingen. Dat is allemaal waar en bovendien kan met genoegen worden geconstateerd dat de accountantsopleidingen aan de Nederlandse universiteiten ondanks jaarlijkse collegegelden van $f 5.600$ tot $f 8.500$ floreren als nooit te voren.

Toch ben ik van oordeel dat een concurrentieanalyse op zijn plaats is. Er is door de opkomst van deze peridoctorale beroepsopleidingen een geheel nieuwe situatie ontstaan. Was voorheen de (academische) accountantsopleiding door inrichting en doelgroep een gemakkelijke koploper, thans past bezinning op de relevante veranderingen in de 'omgeving'. Wie voorsprong heeft moet immer beducht zijn voor de wet van de remmende voorsprong! Er ontstaat een nieuw vraagstuk van gelijkwaardigheid nu registeraccountants in de bestuurslagen van hun cliënten de alumni tegenkomen van deze opleidingen: registercontrollers, masters of financial economics. masters of information management etc.

Als ik het goed zie heeft het accountantsberoep sinds de tijd dat de universitaire twee-fasenstructuur zich aandiende vooral geijverd voor het veiligstellen van de wettelijke basis onder de accreditering tot inschrijving in het accountantsregister. Deze wettelijke basis is dan ook in de wet van 10 september 1993 stevig verankerd en de $A M v B$ op het accountantsexamen van 4 februari 1994 legt in detail vast wat er allemaal geëxami- 
neerd moet worden tot en met de verplichting van de student om twee maial met een scriptie voor de dag te komen. Het examenburealu en het curatorium waken ingevolge wetlelijke opdracht over de kwaliteit van het accountantsexamen: met betrekking tol de praktijkstage zijn reeds nadere maatregelen aangetiondigd. Voorwaar een ideale uitgangspositie om het kwaliteitsniveau voor de toegang tot het beroep te handhaven... maar ook een groot risico van verstarring en bureaucratie. en als zodanig een grool contrast met de flexibele opstelling van de 'concurrentie' die onder de "tucht vall de markt" voortdurend haar bestalansrecht moet bewijzen. Gelukkig geven de valkgroepen Accountancy aan onze universiteiten er blijk van zich bewust te zijn van de noodzalak van voorturende vernieuwing van hel onderwijs. In het Themanummer: Accountantsopleiding in beweging (MAB. okiober 1994) hebben alle relevante instellingen in dit tijdschrift acte de presence gegeven. Alom bestaan er plannen om de aansluiting van opleiding aan de behoeften uit de praktijk te verbeteren en tevens het wetenschappelijk onderzoek in de accountancy te bevorderen. Er wordt gezocht naar flexibeler onderwijsvormen walurbij met name wordt gedacht atan de fase walrin het onderwijs parallel loopt met de prak lijkstige. Deze drang nilar vernicuwing moet uiteraard worden toegejuicht en het is te hopen dalt er een werkbaar evenwicht zal worden gevonden tussen de op centrale toetsing gerichte elementen in de opleiding (voor insiders: de landelijke vraigstukken $A O$ en $L A C$ ) en de creatieve vernieuwing die de betrokken universiteiten roor ogen staat. Ik verwijs hier naar de interessante analyse van Van Manen (1992) walaruit valt af te leiden dat het systeem van landelijke examinering het gevaar in zich draagt dat nieuwe ontwikkelingen eerst met zeer grote vertraging in het onderwijs doordringen.

\section{Faseverschil}

Is er bij de universiteiten dus wel sprake van een open oog voor vernieuwing. des te meer valt het op dalt in geen van de bijdragen in het genoemde themanummer aandacht wordt besteed aan de strategische positionering van de universitaire accountantsopleidingen ten opzichte van de concurrentie" waarvan in het voorgaande een beeld werd gegeven. Slechts in de bijdrage die alkomstig is vall de Vrije Universiteit (VU) te
Amsterdam wordt uitdrukkelijk vermeld dat bij de opret van de afstudeerrichting Accountancy in de doctoralalfase rekening is gehouden met de opleidingseisen voor doorstroom naar de Postdoctorale Controllersopleiding en natar de Postdoctorale EDP-audit opleiding. Zonder dat dit in hun bijdrage expliciet aan de orde komt roepen de auteurs hiermee de indruk op dat zij de beide laatstgenoemde opleidingen in een nevenschikkende positie plaatsen naast de accountantsopleiding (Wilardenburg 1994). Die indruk wordt uiteralard evenzeer gewekt door de naamgeving van het "eindprodukt': Registercontroller, RegisterEDPauditor, Registeraccountant.

Ik ben echter van oordeel dat deze indruk valn nevengeschiktheid nogal wat nuancering behoeft. vooral wat betreft de fase in de beroeps- en carrière-ontwikkeling walarin de studentenpopulatie van de genoemde opleidingen zich bevindt. Aan de algemene opleidingsbrochure van TIAS ontleen ik terzake het volgende citat:

'Het gaat hierbij om opleidingen die een op de beroepsuitoefening gerichte aanvulling zijn op de reguliere (eerste fase) WO- en HBO programmal's. De opleidingen rijn bestemd voor academici en HBO-ers, werkzalam in bedrijven en (overheids) organisaties, die zowel in aansluiting op hun vooropleiding als op hun beroepservaring (vet aangebracht door mij. GB) behoefte hebben aan verbreding en verdieping van kennis en kunde".

Een soortgelijke karakteristiek tekende ik op uit het dankwoord van Prol. Dr. L. Traas na zijn afscheidscollege aan de VU op 24 februari 1995. Terecht werd hem bij die gelegenheid veel lof toegezwaaid voor zijn succesvolle initiatief en implementatie van de Controllersopleiding alan dic universiteit. In zijn slotwoord gaf Traas als wezenlijke karakteristiek van die opleiding aan dat zij zo sterk steunt op de inbreng van de sludenten, die met hun problemen uit eigen crvaringswereld in belangrijke mate de inhoud van het curriculum bepalen. Soortgelijke beleving heb ook ik met betrekking tot het postdoctorale "naervarings" onderwijs dat aan de KUB. in TIAS verband. wordt verzorgd. Ik zie dan ook een duidelijk verschil uussen de fase van maatschappelijke en carrière-ontwikkeling van de studentenpopulatie in de accountantsopleidingen en die in de nieuwe academische beroepsopleidingen. Accoun- 
tancystudenten bevinden zich typisch in de leerling/stagiairefase; voor de opleiding is het belang van de combinatie werken/studeren hier vooral gelegen in de concretisering van de theorie die de studenten aan hun praktische werkzaamheden kunnen ontlenen. De studenten die op de nieuwe academische beroepsopleidingen worden toegelaten zijn er langs diverse wegen reeds op geselecteerd dat zij binnen hun organisatie vergalande verant woordelijkleid dragen of daartoe in concreto zijn geroepen. De wisselwerking tussen theorie en praktijk krijgl daardoor een veel sterker constitutief karakter bij de opzet van de opleiding.

Studenten leren in die opzet ook veel van elkaar ondat een bepaalde probleemstelling snel door verschillende studenten vanuit de eigen werksituatie wordt herkend. Om een hieraan gelijkwaardige studentenpopulatie bijeen te brengen zou binnen het accountantsberoep gedacht moeten worden aan jonge vennoten van accountantskantoren. die binnen hun organisatie zelfstandige verantwoordelijkheid voor hun cliëntenportefeuille dragen en 'in aansluiting...... op deze beroepservaring behoefte hebben aan verbreding en verdieping van kennis en kunde' (zie het citaat hiervoor). Het zal duidelijk zijn dat het hier met name gaat om beroepsgenoten van wie hun omgeving verwacht dat $z i j$ in hun carrière zullen doorgroeien tot leidinggevende functies.

\section{Master of Accountancy?}

Als het accountantsberoep zijn positie 'inter pares" wil behouden dienen wij ons niet te laten misleiden door de schijn van gemeenschappelijke niveaubepaling die de naamgeving met 'register..' ten onrechte oproept. Evenmin mag als vanzelfsprekend worden alangenomen dat het wettelijk geregelde ingangsniveau tot het accountantsberoep een waarborg betekent voor een blijvend adequat professioneel niveatu. Er is daartoe een universitaire opleiding nodig die gekwalificeerde en ervaren accountants (weer) op gelijk niveau brengt met hun gesprekspartners in de organisaties walar zij het beroep uitoefenen. In het licht van het voorgaande duid ik deze opleiding voorlopig maar even aan met de werktitel Master of Accountancy. Met het introduceren van deze opleiding wordt opnieuw afstand genomen van het idee dat registeraccountants "dooreenleverbaar' zijn. Anders dan in de tijd van Kraayenhof gaat het hier echter om een onderscheid in functionele ontwikkeling van betrokkenen vanuit een gemeenschappelijke basis. Het karakter en de doelstelling van deze opleiding brengt immers met zich mee dat zij met name gevolgd zal worden door hen die op zodanig niveau fungeren dat de ermee gemoeide investering binnen hun organisatie kan worden gedragen. Zoals hiervoor aangegeven gaat het om de jonge vennoot van een accountantskantoor of een (ankomend) hoofd interne of overheidsaccountantsdienst, in de leeftijdscategorie rond 35 jaar.

De opleiding tot Master of Accountancy zal in de eerste platats een 'opfriscursus' omvatten terzake van de theorie in de vakgehieden die ook in de primaire accountantsopleiding aan de orde zijn: bedrijfseconomie, organisatie, bestuurlijke informatiekunde, ondernemings- en belastingrecht, accountantscontrole e.d. Het gaat er daarbij vooral om de studenten vertrouwd te maken met de ontwikkelingen in deze vakgebieden sinds zij daarmec - alweer 10 to 15 jaar geleden! - kennis maakten. Vervolgens zal de opleiding zijn gericht op een beleidsmatige (managerial) benadering van de praktijk walarin zij functioneren en het toepassen van moderne inzichten en technieken daarbij. In deze opleidingen blijkt de formule van praktijkgerichte seminars uitstekend te voldoen; daarbij worden actuele vraagstukken aan de orde gesteld in een gezamenlijk optreden van academische docenten en deeltijds docenten uit de praktijk. Er wordt tevens zwaar beroep gedaan op inbreng door de studenten zelf in de vorm van presentaties en participatie in de discussie daarover. Om een indruk te geven van wat hier voor ogen stiat laat ik in willekeurige volgorde en zonder verdere uitwerking een korte opsomming volgen van thema s die op deze wijze aan de orde zouden kunnen komen: Management van professionele organisaties (zoals accountantskantoren); Management en control binnen grote ondernemingen (waarop accountantscontrole behoort aan te sluiten): Trealsury, beleid en verslaggeving (kopzorg voor de moderne ondernemer en dus voor zijn accountant); Claim- en tuchtrecht (kopzorg voor de moderne accountant). Voorts komen uiteraard in aanmerking de ontwikkelingen rond informatisering. milieu. fraudebestrijding etc.; belangrijker dan volledigheid is uiteraard dat bij de keuze kan worden ingespeeld op de actualiteit en - binnen zekere grenzen - op de specifieke behoeften van iedere groep studenten.

Een belangwekkende vralag is nog of gestreefd moet worden naar een afzonderlijke opleiding 
voor accountants dan wel bij voorkeur aansluiting zou moeten worden gezocht bij bijvoorbeeld bestaande of nieuwe controllersopleidingen. Aan dit thema heeft Van Manen eerder in dit tijdschrift aandacht besteed, zij het in een wat andere context dan hier aan de orde is. Ik moge naar zijn overwegingen verwijzen (Van Manen, 1992); de bovenstaande, summiere beschrijving toont in elk geval aan dat er een grote mate van overlapping zal zijn tussen beide opleidingen. Bovendien kan op dit niveau de synergie tussen aanpalende functies nog eens extra bijdragen aan het nuttig effect van de opleiding. Ook mag niet voorbij worden gegaan aan de overweging dat de mobiliteit van professionals de laatste jaren sterk is toegenomen en de overgang van de controlepraktijk naar andere activiteiten binnen of buiten de eigen organisatie frequent voorkomt. Ten slotte moet nog in aanmerking worden genomen dat het zogenaamde netwerkeffect een belangrijk motief vormt om aan dergelijke opleidingen deel te nemen. Al met al acht ik het waarschijnlijk dat mijn werktitel Master of Accountancy slechts een kort leven beschoren zal zijn omdat er combinaties zullen worden gemaakt met andere opleidingen, waarbij de controllersopleiding voor accountants in de algemene controlepraktijk uiteraard 'het dichtst bij huis ligt'.

Het zijn deze overwegingen die ik bij dit eeuwfeest aan het accountantsberoep wil voorleggen; van verdere uitwerking heb ik vooralsnog afgezien in de hoop dat er in het MAB opnieuw een vruchtbare gedachtenwisseling zal ontstaan over de vraag hoe de universitaire accountantsopleiding ook in de volgende eeuw als Primus inter Pares kan blijven gelden. Intussen blijft 'the proof of the pudding in the eating'. Zoals ik bij een andere gelegenheid naar voren heb gebracht (Bak 1994) blijft de hamvraag of de accountantskantoren en -diensten inzien welke investeringen nodig zijn om hun 'professionals' op het niveau te houden van gelijkwaardige gesprekspartners voor hun cliënten. In die kringen zit men ook niet stil!

\section{I T E R A T U U R}

Mey J.L., (1961), De academische en niet-academische vorming van de accountant. MAB 1953. Opgenomen in MAB 1924 - 1960, p. 217 e.v. J.Muusses N.V. Purmerend.

Kraayenhof J., (1961), De opleiding tot accountant. MAB 1955. Opgenomen in MAB 1924 - 1960, p. 257 e.v. J.Muusses N.V. Purmerend.

Regelingen inzake het Accountantsberoep, losbladig afl. 4 (juni 1984), p. 1.1.2.1-05 Kluwer Deventer.

Bak G.G.M., (1986), De universitaire opleiding tot accountant. De Accountant februari, nr 6, p. 257 e.v.

TIAS Tilburgs Instituut voor Academische Studies, Overzicht opleidingen 1994/95, KUB, Tilburg.

VSNU Vereniging van Samenwerkende Universiteiten, Utrecht, Brief 22 januari 1991 aan de colleges van bestuur van de universiteiten inzake toekenning Master's graden.

Diverse auteurs, (1994), Accountantsopleiding in beweging $M A B$ oktober.

Van Manen J.A., (1992), Eén opleiding voor controllers en accountants? MAB jan/febr, p. 2 e.v.

Waardenburg J. en van Zutphen L.C., (1994), Noblesse Oblige, Nieuwe wegen in de opleiding tot registeraccountant aan de Vrije Universiteit. MAB oktober, p. 576.

Bak G.G.M., (1994), All you need is lef. MAB juni, p. 323 e.v. 